\title{
Methodology for the Design of Streamline-Traced External-Compression Supersonic Inlets
}

\author{
John W. Slater* \\ NASA John H. Glenn Research Center, Cleveland, Ohio 44135
}

\begin{abstract}
A design methodology based on streamline-tracing is discussed for the design of externalcompression, supersonic inlets for flight below Mach 2.0. The methodology establishes a supersonic compression surface and capture cross-section by tracing streamlines through an axisymmetric Busemann flowfield. The compression system of shock and Mach waves is altered through modifications to the leading edge and shoulder of the compression surface. An external terminal shock is established to create subsonic flow which is diffused in the subsonic diffuser. The design methodology was implemented into the SUPIN inlet design tool. SUPIN uses specified design factors to design the inlets and computes the inlet performance, which includes the flow rates, total pressure recovery, and wave drag. A design study was conducted using SUPIN and the Wind-US computational fluid dynamics code to design and analyze the properties of two streamline-traced, external-compression (STEX) supersonic inlets for Mach 1.6 freestream conditions. The STEX inlets were compared to axisymmetric pitot, two-dimensional, and axisymmetric spike inlets. The STEX inlets had slightly lower total pressure recovery and higher levels of total pressure distortion than the axisymmetric spike inlet. The cowl wave drag coefficients of the STEX inlets were $20 \%$ of those for the axisymmetric spike inlet. The STEX inlets had external sound pressures that were $37 \%$ of those of the axisymmetric spike inlet, which may result in lower adverse sonic boom characteristics. The flexibility of the shape of the capture crosssection may result in benefits for the integration of STEX inlets with aircraft.
\end{abstract}

\section{Introduction}

Supersonic flight requires inlets that can capture the required amount of supersonic flow, compress the flow, and decelerate the flow for subsonic entry into the turbo-fan engine for the generation of thrust. ${ }^{1,2}$ Externalcompression, supersonic inlets are characterized by a shock system that is mostly external to the internal ducting of the inlet. The deceleration to subsonic speeds occurs through a terminal shock that is approximately a normal shock. At the critical operating point of the inlet, the terminal shock sits at the entrance to the internal ducting of the inlet and the amount of captured flow is matched to the amount of flow required by the engine. A defining aspect of external-compression inlets is the spillage of excess externally to the internal ducting of the inlet. This occurs when the engine requires less flow than the design condition. The terminal shock is pushed upstream and the spillage occurs at subsonic conditions between the terminal shock and the start of the internal ducting of the inlet.

The design and analysis of external-compression supersonic inlets has been a topic of research and development for over 60 years. ${ }^{3}$ Pitot, two-dimensional, and axisymmetric spike inlets have been the primary choices of inlet types for past aircraft concepts. A pitot inlet uses a normal terminal shock to decelerate the flow to subsonic conditions. The Lockheed-Martin F-16 is an example of an aircraft with a pitot inlet. ${ }^{4}$ A two-dimensional inlet uses one or more ramps to create an oblique shock system that decelerates the flow to a lower supersonic Mach number ahead of the normal terminal shock. The Boeing F-15 is an example of an aircraft with a two-dimensional inlet. ${ }^{5}$ An axisymmetric spike inlet uses an axisymmetric spiked centerbody to create a conical shock system to decelerate the flow. The Convair B-58 was an example of an aircraft with an axisymmetric spike inlet. ${ }^{6}$

Another approach for supersonic inlet design is to incorporate streamline tracing. Evvard and Maslen provided one of the earliest discussions on the use of streamline tracing for the design of compressive surfaces for inlets. ${ }^{7}$ The general idea of streamline tracing is to integrate streamlines through a compressive, supersonic flowfield to form a surface which can be replaced by the solid surface of the eternal supersonic diffuser. Mölder and Szpiro

\footnotetext{
${ }^{*}$ Aerospace Engineer, Inlet and Nozzle Branch, MS 5-12, 21000 Brookpark Road, AIAA Senior Member.
} 
studied an inlet based on an axisymmetric flow field proposed by Busemann in which the supersonic inflow and outflow are uniform and directed along the axis-of-symmetry. ${ }^{8}$ The streamline-tracing technique has been applied by various researchers to develop inlets for hypersonic missiles and aircraft. ${ }^{9,10}$ The technique allows the generation of a wide variety of surface shapes depending on the shape of the curves from which the streamlines originate. The surfaces are potentially "three-dimensional" surfaces if the generated surfaces are non-planar and asymmetric. Thus, streamline tracing can facilitate improved integration of the inlet with the aircraft.

The use of streamline tracing for external-compression inlets operating below Mach 2.0 requires consideration of the normal terminal shock within the shock system of the supersonic diffuser. The oblique shock at the outflow is replaced with a stronger terminal shock that yields subsonic outflow. Some past inlet design studies have considered streamline-traced external-compression inlets. Sanders et al studied the use of streamline tracing for Mach 2.35 flight as part of the NASA High-Speed Research Program in the late 1990's and a patent was released in $2004 .{ }^{11}$ A parallel effort at NASA resulted in the so-called "Parametric Inlet", which used an external-compression supersonic diffuser that compressed the flow isentropically by turning the flow toward the axis-of-symmetry. The curve from which the streamlines originated was located in the throat and had the shape of a partial co-annular section. This yielded flat sidewalls which did not contribute to the supersonic compression. The Parametric Inlet underwent an extensive design and analysis process involving CFD and a wind-tunnel model was fabricated and tested in 2004. ${ }^{12}$ The supersonic business jet concept being studied by the Aerion Corporation explored the use of an inlet designed using streamline tracing techniques. ${ }^{13,14}$

The objective of this paper is to present a methodology for the design of streamline-traced, external compression (STEX) inlet concepts suitable for supersonic commercial flight below Mach 2.0. The paper is organized as follows. Section II discusses the design methodology for STEX inlets. Section III discusses the SUPIN (SUPersonic INlet design and analysis) tool within which the design methodology has been implemented. Section II also discusses the Wind-US computational fluid dynamics (CFD) code, which is used to provide higherfidelity analysis of the inlet flow fields. Section IV discusses a design study involving two STEX inlets of differing capture cross-sections which were designed and analyzed using SUPIN. Also included in the design study are three traditional inlets consisting of an axisymmetric pitot inlet, a two-dimensional inlet, and an axisymmetric spike inlet. The performance of the STEX inlets is compared to that of the traditional inlets. The inlet performance is characterized by the inlet flow rate, total pressure recovery, and cowl drag. The inlet flow fields are also simulated using the Wind-US code as a means of verifying the results obtained from the SUPIN tool. Finally, Section V offers some concluding remarks.

\section{STEX Inlet Design Methodology}

This section presents the methodology for designing STEX inlets. STEX inlets contain much of the same parts as traditional inlets, but differ in their placement and operation. The methodology designs the inlets based on specified freestream and engine face conditions representing the upstream and downstream boundary conditions, respectively, of the inlet design problem. The methodology is based on a parent flowfield, which in this case is the axisymmetric Busemann flowfield, through which streamlines are traced to create a supersonic compression surface. The methodology modifies the streamlined supersonic diffuser to establish an external terminal shock. Subsonic diffusion in the throat and subsonic diffuser decelerates and compresses the flow into the engine face. A cowl exterior is created to establish estimates for the cowl drag.

\section{A. STEX Inlet Coordinates and Stations}

Figure 1 shows an example of a STEX inlet designed for Mach 1.6 freestream conditions using circular tracing curves. The parts of the inlet include the supersonic diffuser, throat, and subsonic diffuser. The freestream is designated as station 0 . Station $\mathrm{L}$ is located just upstream of the inlet. The nose is the forward-most point of the leading edge on the symmetry plane. The cowl lip is the rearward-most point of the leading edge on the symmetry plane. The cowl lip marks the start of the internal duct of the inlet and is designated as station 1. The supersonic diffuser extends between stations $\mathrm{L}$ and 1 . The methodology creates the supersonic diffuser about the inlet axis positioned at coordinate $y_{\text {inlet }}$. The throat is the forward portion of the internal ducting and extends between station 1 and station SD, which is the location of the start of the subsonic diffuser. The cross-section at station SD is constructed about an axis with coordinates of $(x, y)_{\mathrm{SD}}$. The subsonic diffuser extends until station 2 , which is the engine face. The engine face is constructed about the engine axis located at $(x, y)_{\mathrm{EF}}$. 


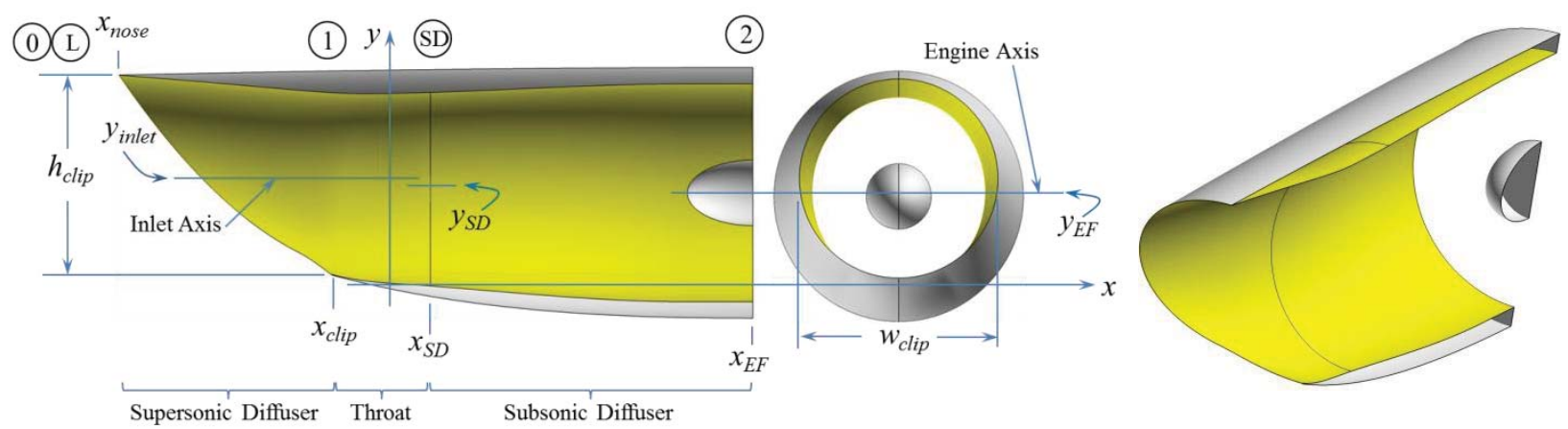

Figure 1. Schematic of a streamline-traced external-compression

\section{B. Freestream and Inlet Inflow Conditions}

The flow conditions at the inflow to the inlet at station $\mathrm{L}$ establish the upstream aerodynamic boundary conditions for the design of the inlet. The conditions at the inflow may differ from the freestream conditions at station 0 due to the effects of the portion of the aircraft forward of the start of the inlet. Such effects depend upon the installation of the propulsion system onto the aircraft. The freestream airflow ahead of the aircraft may wash over the portion of the aircraft ahead of the inflow station of the inlet. The freestream flow conditions are assumed to be uniform and are established through specification of the Mach number $\left(M_{0}\right)$ and altitude $\left(h_{0}\right)$. For the inlets discussed in this paper, the freestream Mach number is set as $M_{0}=1.6$ and the altitude is set as $h_{0}=40000$ feet. These conditions are representative of those of interest for current commercial supersonic flight and are used in this paper to demonstrate the design methodology rather than design an inlet for a specific application. The standard atmosphere provides the corresponding thermodynamic properties $\left(p_{0}, T_{0}\right)$. The discussions of this paper assume an isolated inlet such that the conditions at the inflow to the inlet are equivalent to the freestream conditions (i.e. $M_{L}=$ $M_{0}$ ). The inflow to the inlet at station $\mathrm{L}$ is assumed to be uniform. It is also assumed that the inlet axis is aligned with the inflow, which means that the angle-of-attack and angle-of-sideslip for the inlet are zero.

\section{Engine-Face Conditions}

The engine-face conditions establish the downstream aerodynamic and geometric boundary conditions for the design of the inlet. An inlet is typically designed for a specified engine. The engine face is designated as station 2, as shown in Fig. 1. For this paper and the demonstration of the inlet design methodology, the engine face is circular with a diameter of $D_{2}=3.0$ feet. A spinner is assumed about the hub of the engine to have an elliptic profile with a diameter at the engine face of 0.9 feet and a length of 0.9 feet. The corrected engine-face flow rate is specified through the value of the mass-averaged engine-face Mach number, which here is chosen to be $M_{2}=0.52$.

\section{Axisymmetric Busemann Flowfield}

One can theoretically choose any appropriate flowfield as the parent flowfield for the streamline tracing. Here the axisymmetric Busemann flowfield is used as the parent flowfield. ${ }^{8,9,10}$ Figure 2 shows a schematic of the Busemann flowfield. The uniform axial inflow at the supersonic Mach number $M_{L}$ is decelerated and turned toward the axis through a series of isentropic waves. A free-standing conical shock turns the flow back to the axial direction to yield a uniform axial outflow at the supersonic Mach number $M_{B e x}$. The conical flowfield between the conical shock and the inflow is determined through a solution of the Taylor-Maccoll equations with the rays centered at the focal point. ${ }^{15}$ An iteration scheme is performed on the angle of the conical shock wave $\left(\beta_{B e x}\right)$ to obtain the desired inflow Mach number $\left(M_{L}\right)$ for the specified outflow Mach number $\left(M_{B e x}\right)$. The leading Mach wave is at the conical angle of $\beta_{B l e}$, which is consistent with the Mach angle $\mu_{L}$ corresponding to the inflow Mach number $\left(M_{L}\right)$. The focal point of the Busemann flowfield becomes the origin of the global $(x, y, z)$ coordinate system for the inlet. The choice of the Busemann flowfield is based on: 1) the solution of the flowfield is computationally quick and efficient, 2) the flowfield represents an inward-turning compressive flowfield, 3) the supersonic compression occurs three-dimensionally about the axisymmetric axis, and 4) the outflow is uniform and axial, which simplifies the placement of the tracing curves for the streamline tracing, as discussed in the next sub-section.

\section{E. Streamline Tracing}

A supersonic compression surface can be formed by tracing streamlines through the Busemann flow field. The methodology involves defining tracing curves at the outflow and then integrating the streamlines in the upstream 
direction through the flow field. The tracing curves form a closed circuit on a plane that is perpendicular to the outflow. Here, two tracing curves are used that are defined using separate super-ellipses for the top and bottom segments of the closed circuit. The super-ellipse tracing curves are characterized by the length of the semi-major axis $\left(a_{S T}\right)$, the lengths of the semi-minor axes for the top $\left(b_{\text {STtop }}\right)$ and bottom $\left(b_{\text {STbot }}\right)$ curves, and the super-ellipse parameters for the top $\left(p_{\text {STtop }}\right)$ and bottom $\left(p_{\text {STbot }}\right)$ curves. ${ }^{16}$ The factors $R_{\text {STtop }}$ and $R_{\text {STtop }}$ are ratios of the semi-minor and semi-major axis length in the form of $R_{\text {STtop }}=b_{S T \text { top }} / a_{S T}$, such that $b_{\text {STtop }}=R_{S T \text { top }} a_{S T}$ and $b_{S T b o t}=R_{S T b o t} a_{S T}$. A parameter value of $p_{\text {STtop }}=2$ yields an ellipse. As the parameter $p_{\text {STtop }}$ increases, the curve becomes more rectangular. Figure 3 shows two sets of tracing curves. The top curves are colored in red and the bottom curves are colored in blue. The tracing curves on the left consist of circular arcs for both the top and bottom curves. The tracing curves on the right have a circular arc for the bottom curve; however, the top curve is a super-elliptic curve with the parameter equal to $p_{\text {STtop }}=3$. In addition, the top tracing curve has $R_{\text {STtop }}=0.5$. The effect of these values is to flatten the top tracing curve.

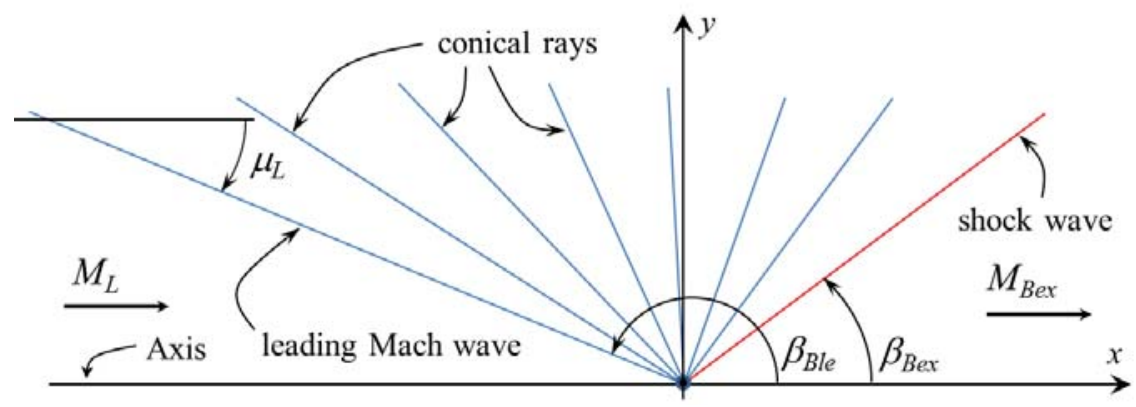

Figure 2. Axisymmetric Busemann flow field.

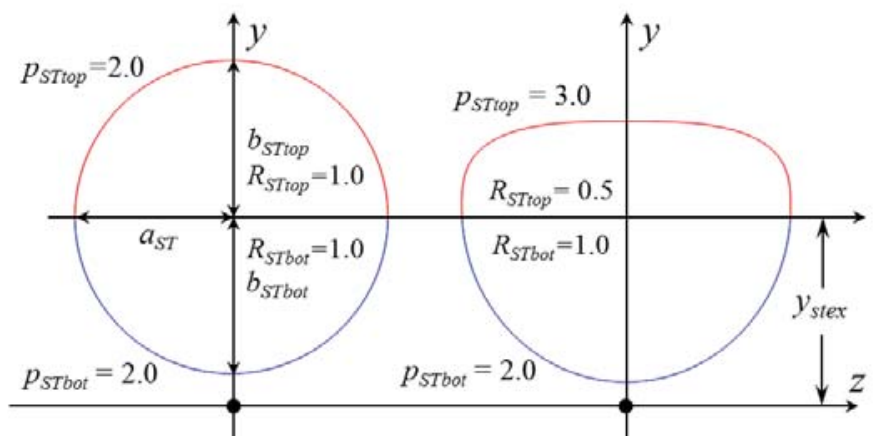

Figure 3. Two examples of tracing curves defined using super-ellipses.

The tracing curves are defined in a local coordinate system and then translated and rotated for placement on a plane within the outflow of the Busemann flowfield that is perpendicular to the axis-of-symmetry of the Busemann flowfield. The tracing curves are symmetric with respect to the $z=0$ plane but can be offset from the axis-ofsymmetry of the Busemann flowfield by a value $y_{\text {stex }}$. The streamlines are created by starting at points distributed along the tracing curves and integrating through the local velocity field in the upstream direction. Figure 4 shows an example of the integration of the streamlines through the flowfield at three points along the tracing curves. The streamlines are shown as dashed lines. Each point on the tracing curve is associated with a circumferential angle about the axis-of-symmetry. Thus, the integration of each streamline is a planar integration problem.

The upstream integration is performed until the conical angle of $\beta_{\text {trunc }}$, which is defined as

$$
\beta_{\text {trunc }}=\beta_{\text {Bex }}+F_{\text {strunc }}\left(\beta_{\text {Ble }}-\beta_{\text {Bex }}\right)
$$

where the factor $F_{\text {strunc }}$ specifies the amount of truncation of the streamline tracing. A value of $F_{\text {strunc }}=1.0$ will cause the streamline tracing to extend to the leading Mach wave corresponding to the inflow Mach number $\left(M_{L}\right)$ and an initial surface slope aligned with the axis-of-symmetry. A truncation with $F_{\text {strunc }}<1.0$ will stop the streamline tracing before the leading Mach wave with a lower inflow Mach number and non-axial slope. This may be desirable when one desires a shorter supersonic compression surface and an initial shock wave at the leading edge rather than a Mach wave.

By definition, no flow crosses the streamlines, and so, the network of streamlines can be replaced by a solid surface defining the surface of the external supersonic diffuser. The circuit of upstream endpoints of the streamlines 
defines the leading edge of the supersonic diffuser. The axial projection of the leading edge of the external supersonic diffuser onto a plane perpendicular to the axis-of-symmetry defines the shape of the capture cross-section of the inlet. The area of the capture cross-section is the theoretical capture area of the inlet.

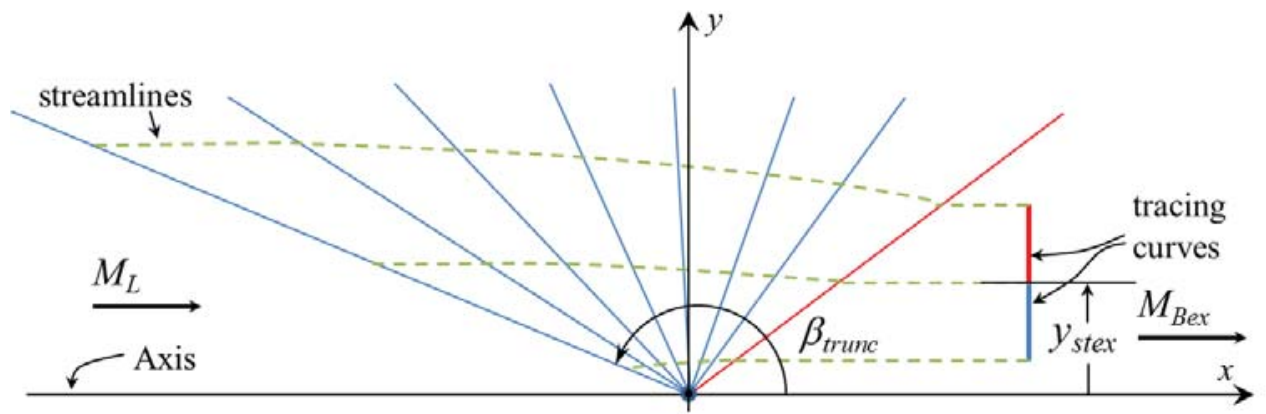

Figure 4. Integration of streamlines from the tracing curve.

The shape of the tracing curves and the placement of the tracing curve with respect to the axis-of-symmetry allows for the creation of a variety of supersonic diffuser shapes for the capture cross-sections. For an external supersonic diffuser, the tracing curve is offset from the axis-of-symmetry such that the streamlines will not contain the focal point of the Busemann flow field. Figure 4 shows the tracing curve "above" the axis-of-symmetry. Figure 5 shows two examples of streamline-traced inlets created from the tracing curve shapes of Fig. 3 . The placement of the tracing curves created inlets with the leading edge of the inlet swept back. This swept-back aperture allows for subsonic spillage downstream of the terminal shock, which removes excess inlet flow for an external-compression inlet. Further, the flexibility in the shape of the tracing curve may be beneficial for integration of the inlet onto the aircraft. For example, the inlet with a flatter leading edge, may integrate better along a fuselage or wing.
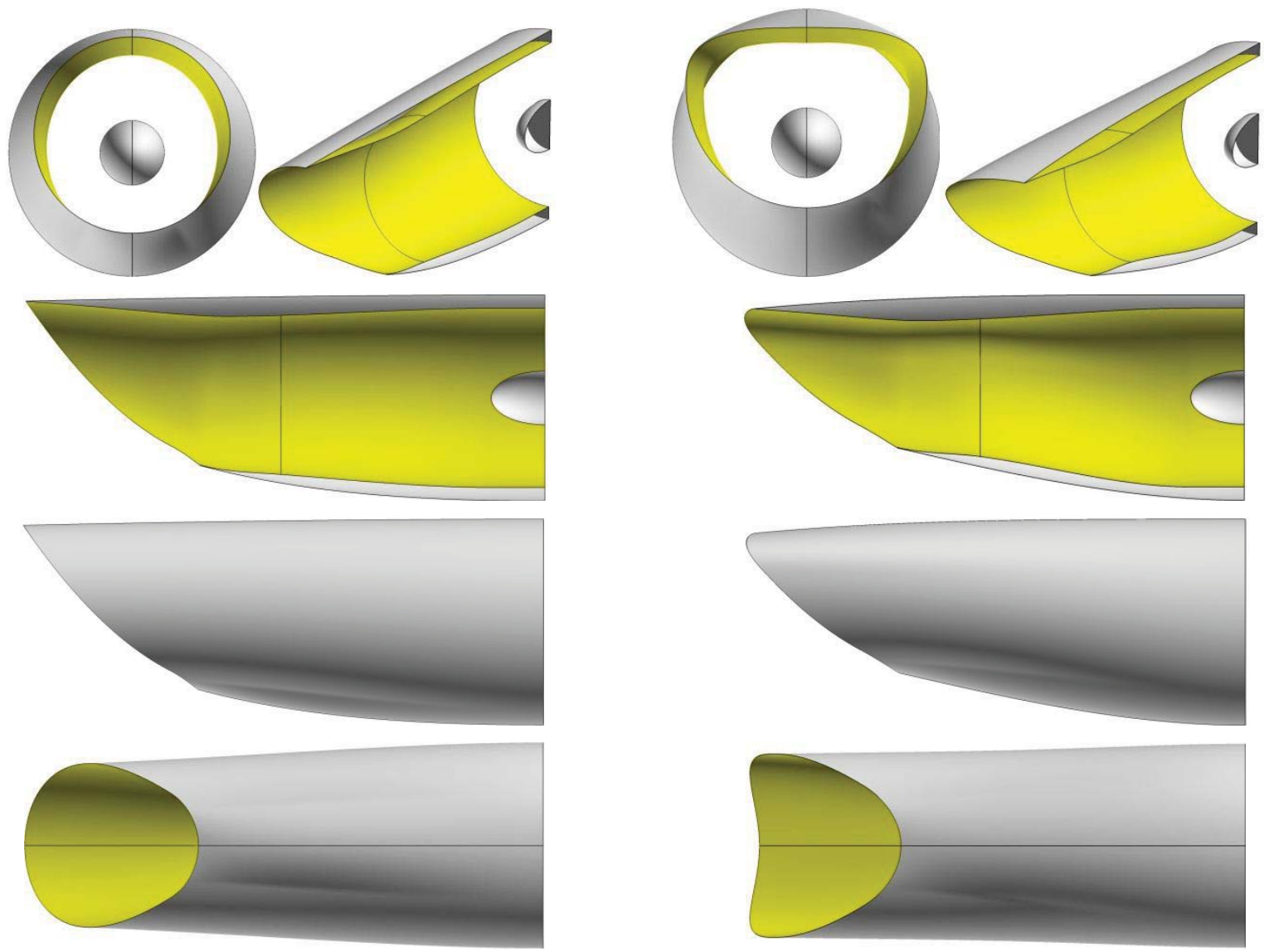

Figure 5. Examples of streamline-traced inlets with the tracing curves of Fig. 3. 


\section{F. External-Compression Shock System}

The streamline-tracing method of the previous section creates a supersonic compression surface with a supersonic outflow within the start of the internal ducting of the inlet. For an external-compression inlet, a terminal shock is desired at the entrance to the internal ducting to allow subsonic flow into the internal ducting of the inlet and subsonic spillage at sub-critical conditions. Four modifications to the original streamline-traced surface are introduced to provide a shock system more suitable for external compression: 1) creation of a subsonic cowl lip region, 2) imposition of an initial angle of the compression surface at the leading edge, 3) adjustment of the shoulder cross-section, and 4) sculpting of the supersonic compression surface between the leading edge and the shoulder cross-section.

The first modification involves establishing a subsonic cowl lip over the downstream portion of the inlet leading edge where subsonic spillage is expected to occur. Figure 6 shows a representation of the terminal shock within the inlet. The terminal shock is represented as the blue shaded shape. The terminal shock is mostly contained by the supersonic compression surface of the inlet, but spills outside of the inlet over the portion of the leading edge that is the most downstream segment. This spillage is useful in that it provides a stable mechanism by which excess engine flow can bypass the inlet. The spillage is subsonic since it is downstream of the terminal shock. The spillage is contained to spill past this region and this could be used to tailor the direction of the spillage such as to enhance integration of the propulsion system with the aircraft or enhance low sonic boom characteristics.

The circumference of the leading edge of the inlet can be divided into a supersonic leading edge segment that encounters the supersonic inflow and the subsonic cowl lip segment that is washed over by the subsonic spillage. The supersonic leading edge retains the shape as established by the original streamline-traced surface with the addition of an elliptic profile of small thickness to create a blunt leading edge. The circumferential extent of the subsonic cowl lip is specified through the input factor $\Delta \phi_{s t c l}$, which is the angle of a circular arc centered about the axis of the tracing curve.

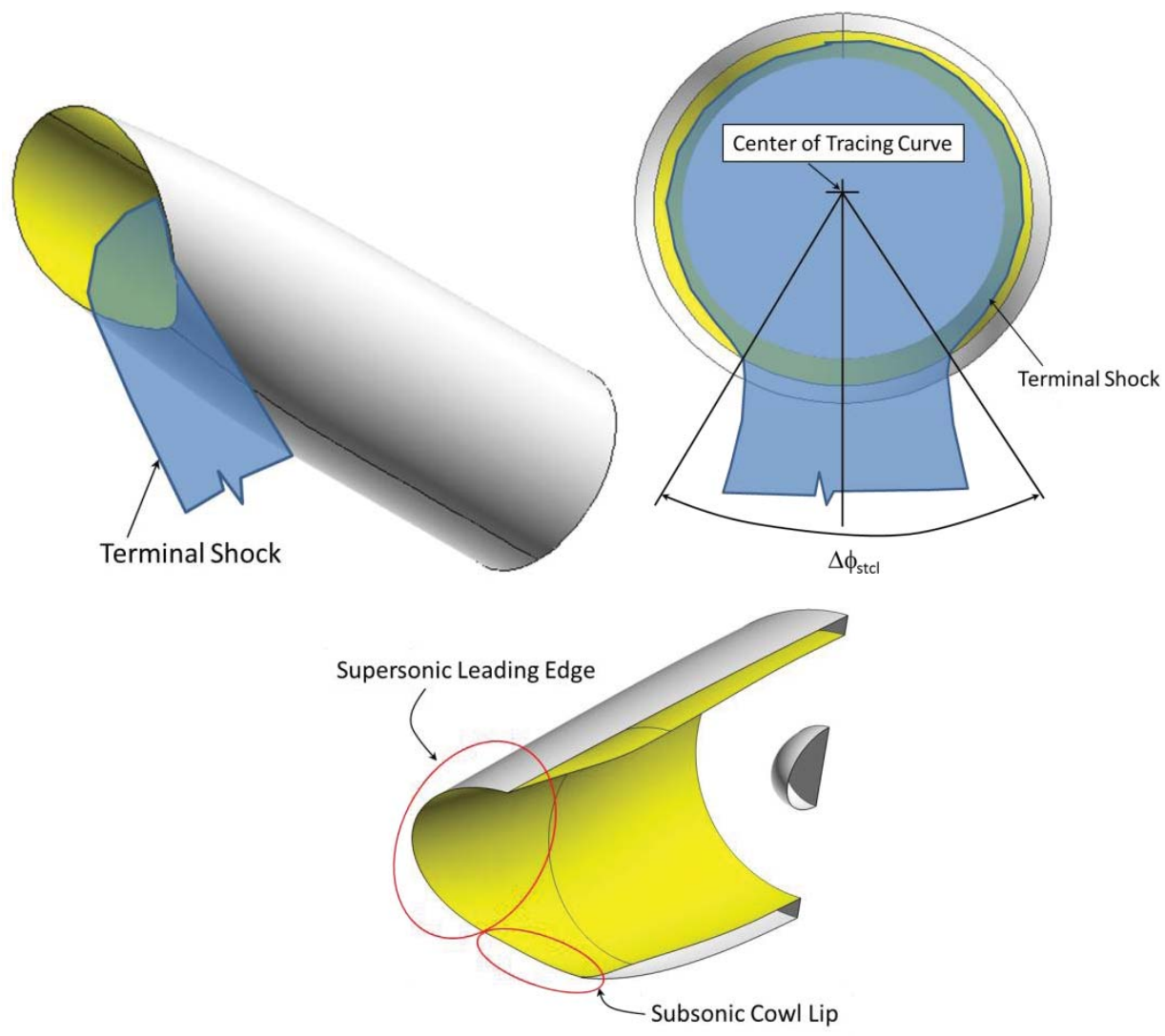

Figure 6. The supersonic leading edge and the subsonic cowl lip.

The subsonic cowl lip can be modified to be better suited to the subsonic flow conditions of the subsonic spillage. This includes making the subsonic cowl lip thicker and orienting the angle of the cowl lip in the direction 
of the local subsonic flow. The method for establishing the subsonic cowl lip involves defining a subsonic cowl lip profile at the inlet symmetry plane. This profile is then blended over the extent of the subsonic cowl lip with the profile of the supersonic cowl lip at the outer bounds of the subsonic cowl lip. Figure 7 shows the original supersonic cowl lip profile and the modified subsonic cowl lip profile at the symmetry plane. Both profiles are defined using ellipses for the interior and exterior surfaces. The ellipses of the subsonic cowl lip have semi-major and semi-minor axis lengths of $a_{\text {stcl }}$ and $b_{\text {stcl }}$, respectively. The profile is oriented with respect to the inlet axis by an angle of $\theta_{\text {stcl }}$. The profile of the subsonic cowl lip can be translated with respect to the supersonic cowl lip profile using the input factors $\Delta x_{\text {stcl }}$ and $\Delta y_{\text {stcl. }}$. The translation allows modification of the capture cross-section in the subsonic cowl lip region. The surface of the subsonic cowl lip is created by a transition of the ellipse parameters over the circumferential extent of the subsonic cowl lip between the symmetry plane and the outer boundaries of the subsonic cowl lip.

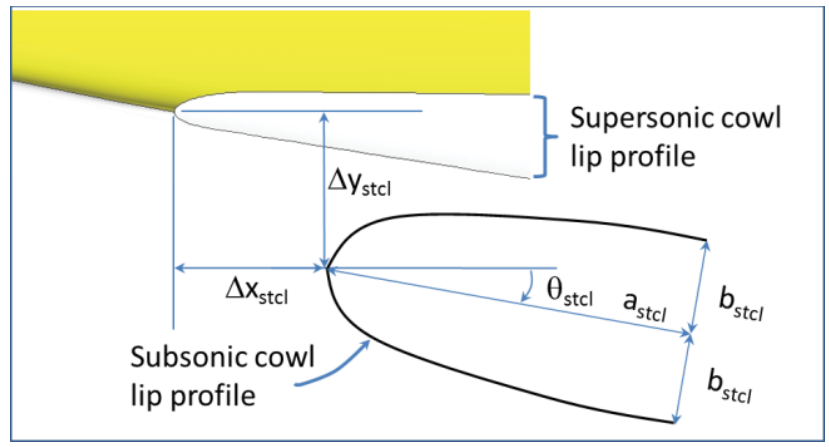

Figure 7. Defining the profile of the subsonic cowl lip.

The second modification of the original streamline-traced surface involves increasing the initial surface angle of the supersonic compression surface at the supersonic leading edge to introduce an oblique shock wave that provides for a stronger initial compression. The modification involves calculating a desired surface angle, $\theta_{\text {stle, }}$, at the symmetry plane of the inlet at the forward-most point of the supersonic leading edge. This point is referred to as the "nose" of the inlet. The surface angle for the remainder of the supersonic leading edge is determined from a blending between the angle at the symmetry plane $\left(\theta_{s t l e}\right)$ to the angle of the original streamline-traced surface at the start of the subsonic cowl lip. The angle $\theta_{\text {stle }}$ is determined from two-dimensional oblique shock theory with consideration of the geometry of the inlet profile at the symmetry plane, as shown in Fig. 8. The intent of the design is to create an oblique shock originating at the nose and directed toward the cowl lip point at $(x, y)_{\text {stcl }}$ defined by the subsonic cowl lip. The oblique shock has a wave angle of $\beta_{\text {stle, }}$ which is specified as part of the design intent. A larger shock angle may be specified to place the oblique shock ahead of the cowl lip, which may be beneficial for enhanced flow stability. With the inflow Mach number $M_{L}$ and shock angle $\beta_{\text {stle }}$ known, oblique shock theory can be used to compute $\theta_{\text {stle. }}{ }^{15}$

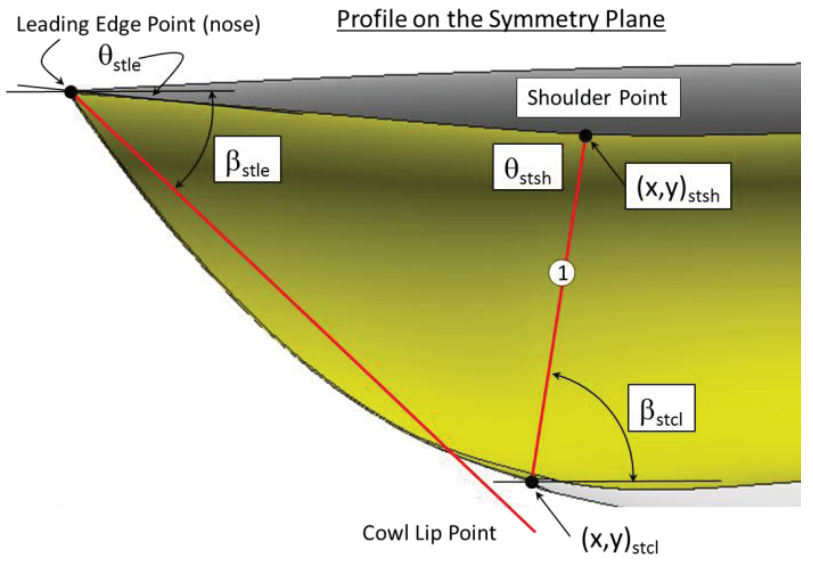

Figure 8. Cowl lip and shoulder modifications. 
The third modification involves establishing the cross-section for station 1. At the symmetry plane, station 1 extends from the cowl lip point $(x, y)_{\text {stcl }}$ to the shoulder point $(x, y)_{\text {stsh }}$ at an orientation of $\beta_{\text {stcl }}$, as shown in Fig. 8 . The cross-section at station 1 is a planar area defined on the boundaries by two super-ellipse curves constructed in the same manner as the tracing curves as shown in Fig. 3, but with specified super-ellipse factors for top and bottom super-ellipse curve $\left(a_{S I}, b_{t o p S I}, b_{\text {bot } S I}, p_{\text {topSI }}, p_{\text {botsI }}\right)$. The design methodology assumes that a normal terminal shock is positioned at station 1, which is the critical operating point of the inlet in which there is zero subsonic spillage and maximum captured airflow. The supersonic compression occurs between the leading edge of the inlet and station 1 with the mass-averaged supersonic Mach number upstream of the terminal shock designated as $M_{E X}$. The Mach number at station $1\left(M_{l}\right)$ is the mass-averaged subsonic Mach number downstream of the terminal shock. The design methodology involves establishing the cross-section at station 1 such that the desired value of pre-shock Mach number $M_{E X}$ is obtained. The cross-section at station 1 is assumed to have the same aspect ratios as the tracing curves. The area of the cross-section at station $1\left(A_{l}\right)$ can be determined based on the leading edge shock total pressure losses and the assumption of isentropic compression between the leading edge and the terminal shock with the deceleration of the flow to the pre-shock Mach number $M_{E X}$. Thus, with the area $A_{l}$ known, the dimensions of the cross-section at station 1 and the coordinates of the shoulder point $(x, y)_{\text {stsh }}$ can be determined.

The fourth modification involves establishing the compression surface between the leading edge and station 1 . This surface is created as a network of Non-Uniform Rational B-Splines (NURBS) curves for which the start and end coordinates and slopes are known. The slope of the shoulder at station 1 at the symmetry plane $\left(\theta_{s t s h}\right)$ is specified as an input factor. The slopes along the remainder of the circumference at station 1 are determined through a blending between the angle $\theta_{\text {stsh }}$ and a value of zero at the bottom of the circumference. With the coordinates and angles known at the leading edge and station 1, a supersonic compression surface can be created.

\section{G. Throat and Subsonic Diffuser}

The throat provides the transition from the supersonic external-compression shock system ending at station 1 to the start of the subsonic diffuser at station SD. Between station 1 and SD the flow is assumed to be subsonic. The cross-section at station SD is a planar area bounded by super-ellipses defined in the same manner as the tracing curve. The location of the center point of station $\mathrm{SD},(x, y)_{S D}$, is specified along with an area ratio $A_{S D} / A_{1}$. With the area $A_{S D}$ known, the parameters of the super-ellipses at station SD can be determined.

The subsonic diffuser transitions between the geometry of station SD and the engine face at station 2. The center of the engine face $(x, y)_{E F}$ is an input factor. Thus, the placement of the relative positions of stations SD and 2 becomes part of the design process.

\section{H. Cowl Exterior}

The integration of the inlet with the aircraft has a great effect on the shape of the exterior cowling about the inlet and the level of drag on the exterior of the inlet. The design methodology discussed here considers only an isolated inlet. However, the design methodology within SUPIN does create a representative cowl exterior for the inlet and calculates the cowl drag about that cowl exterior. While the computed cowl drag is not an absolute measure of the drag, it can be used to provide a relative measure of the cowl drag of various inlets designed under the same conditions and design factors.

The design methodology creates a cowl exterior surface for the streamline-traced inlets by sculpting a smooth surface from the leading edge and cowl lip to a downstream cross-section. The downstream cross-section is circular with a diameter that is specified as a factor $F_{r c e x}$ of the engine-face diameter. The input factor $F_{r c e x}$ is selected to provide the proper volume for inlet structure. The $x$-coordinate of the downstream station can be either specified or located at the engine-face position. The cowl exterior surface is created as a network of NURBS curves. Each curve starts at the leading edge with a surface angle calculated based on the local geometry. Within the supersonic leading edge this exterior angle is approximately the slope required to blend the leading edge with the downstream crosssection. Within the subsonic cowl lip, the exterior angle is approximately the local orientation angle of the cowl lip profile. At the downstream cross-section, the exterior angle is axial.

The cowl exterior surfaces of two STEX inlets can be seen in Fig. 5. The images on the left of Fig. 5 show the isometric and side views of a STEX inlet created with a circular tracing curve. The images on the right of Fig. 5 show the isometric and side views of a STEX inlet created with a flat-top tracing curve.

\section{Computational Design and Analysis Tools}

The design methodology described above was implemented into the SUPIN tool. The SUPIN tool creates the inlet geometry and provides low-order estimates of inlet performance, which includes the inlet flow rates, total pressure recovery, and cowl drag. The methods of computational fluid dynamics (CFD) as implemented in the 
Wind-US CFD code solve for flow variables on a set of grid points within a flow domain about and within the inlets. Such flow fields can provide higher-fidelity values of the inlet performance measures. The results from the CFD analyses provide a means to check the veracity of the methods within SUPIN. The CFD solutions also allow visualization of the flowfield to better understand the shock structures, boundary layers, and other flow features within and about the inlet. Of particular interest is the distribution of total pressure over the engine face. This distribution is used to assess the total pressure distortion at the engine face. The characterization of the distortion determines in part the compatibility of the inlet with the engine.

\section{A. The SUPIN Tool}

The SUPIN tool is a Fortran 90 computer code developed by the author that uses analytical, numerical, and empirical methods to design the geometry and estimate the aerodynamic performance of supersonic inlets. The geometric and aerodynamic conditions for the inlet design form a set of design factors, which are specified in an ASCII input data file. The SUPIN tool reads the input data file and sizes the inlet through an iterative procedure. As part of the design methodology, SUPIN provides estimates of inlet aerodynamic performance, which includes the inlet flow rates, total pressure recovery, and inlet drag. Within an iteration, the geometry of the inlet and its corresponding aerodynamic performance are computed. The iterations proceed until the desired corrected airflow through the engine face is obtained. SUPIN is able to design traditional axisymmetric pitot, two-dimensional, and axisymmetric spike external-compression inlets, in addition to, the streamline-traced inlets. The geometry modeling uses planar constructs and NURBS curves to form the profiles and surfaces of the inlets. The aerodynamic modeling uses flow continuity, shock theory, method-of-characteristics, and empirical data to characterize the inlet performance. The SUPIN tool generates an output data file summarizing the geometry and aerodynamic performance of the inlet. The SUPIN tool also generates files of the surface grids in Plot3D and stereo-lithography file (STL) formats. ${ }^{17}$ These files can be used for visualization of the inlet geometry. The SUPIN tool can also generate three-dimensional, multi-block, structured grids for use with CFD methods.

\section{B. The Wind-US CFD Code}

The Wind-US CFD code solves the Reynolds-Averaged Navier-Stokes (RANS) equations for a multi-block, structured grid for a flow domain about and within the inlet. ${ }^{18}$ Figure 9 shows an example of the flow domain used for streamline-traced inlets. The flow domain has inflow boundaries upstream and about the inlet where freestream boundary conditions are imposed. At the end of the cowl exterior, the domain has an outflow boundary where supersonic extrapolation boundary conditions are imposed. The internal and external surfaces of the inlet form a portion of the boundary of the flow domain where adiabatic and no-slip viscous wall boundary conditions are imposed. Downstream of the engine face, a converging-diverging nozzle section is added to the flow domain to regulate the back-pressure within the inlet. The nozzle throat is set to be choked so that the outflow boundary of the nozzle is supersonic, which allows a non-reflective extrapolation boundary condition to be imposed.

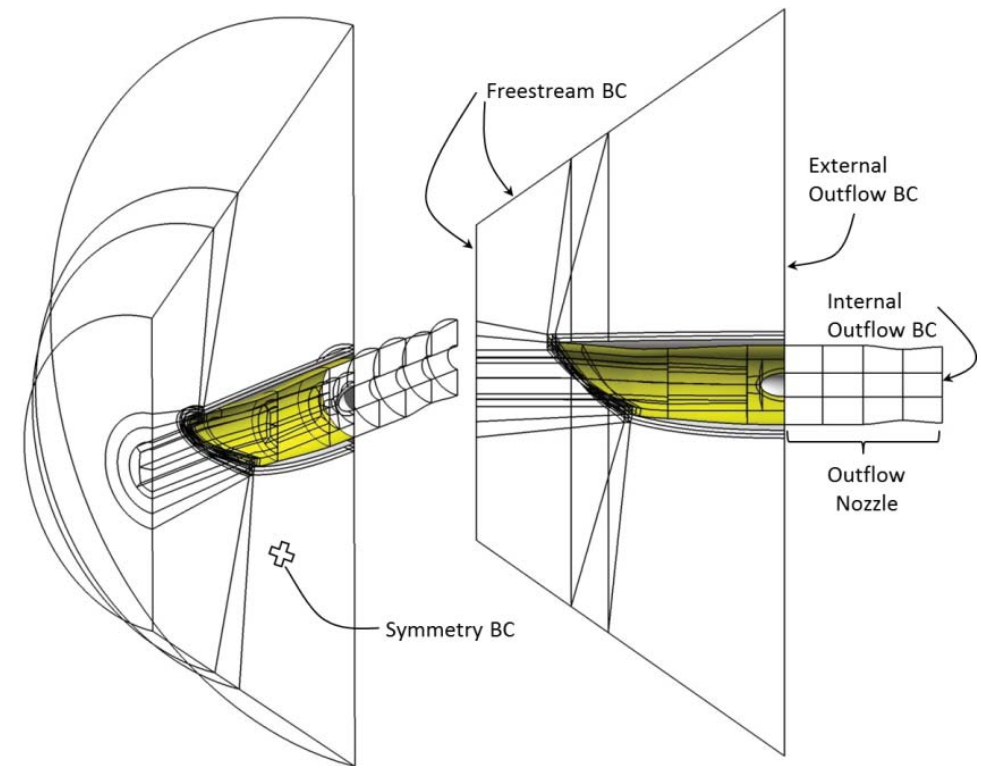

Figure 9. Flow domain and boundary conditions for CFD analysis. 
The Wind-US uses a cell-vertex, finite-volume representation for which the flow solution is located at the grid points. In Wind-US, the RANS equations are solved using an implicit time-marching algorithm with a first-order, implicit Euler method using local time-stepping. The flowfield is initialized at all grid points with the flow conditions associated with station $\mathrm{L}$ at the inflow to the inlet. In Wind-US, local time-stepping is used within the marching time steps to converge the flow solution to a steady-state flowfield. The temperatures were assumed to be within the limits to allow the use of the ideally-perfect air model. The inviscid fluxes of the RANS equations were modeled using a second-order, upwind Roe flux-difference splitting method. The flow is assumed to be turbulent with the turbulent eddy viscosity calculated using the two-equation Menter shear-stress transport (SST) model.

\section{Inlet Design Study}

An inlet design study was conducted to demonstrate the design methodology for the STEX inlets and compare the size and performance of STEX inlets to that of traditional inlet types. The SUPIN tool was used to design three traditional inlets and two STEX inlets. All five inlets were designed for the same freestream and engine-face conditions, as indicated in Section II. Further, the inlets were designed using the same values for many of the geometric design factors for the cowl lips, throat, subsonic diffuser, and cowl exterior. Thus all of the inlets had a common basis, but different shapes according to the respective design methodologies for the type of inlet. Both SUPIN and Wind-US were used to obtain values of the inlet performance measures. The results allowed a direct comparison of the sizes and performance of the STEX inlets in reference to the traditional inlets.

The traditional inlets included an axisymmetric pitot inlet, a two-dimensional inlet, and an axisymmetric spike inlet. Figure 10 shows the three traditional inlets. The two STEX inlets included one inlet with circular tracing curves, which will be referred to as the STEX-Circular inlet, and one inlet with tracing curves with a flatter shape for the top curve, which will be referred to as the STEX-Flattop inlet. The inlets shown in Fig. 5 shows these two STEX inlets, which were created using the tracing curves of Fig. 3. SUPIN was used to size the inlets and create the surface grids for each inlet.

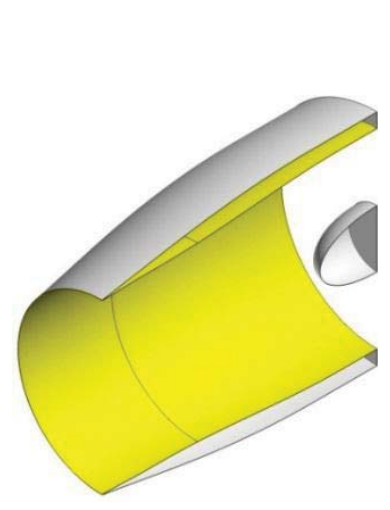

(a)

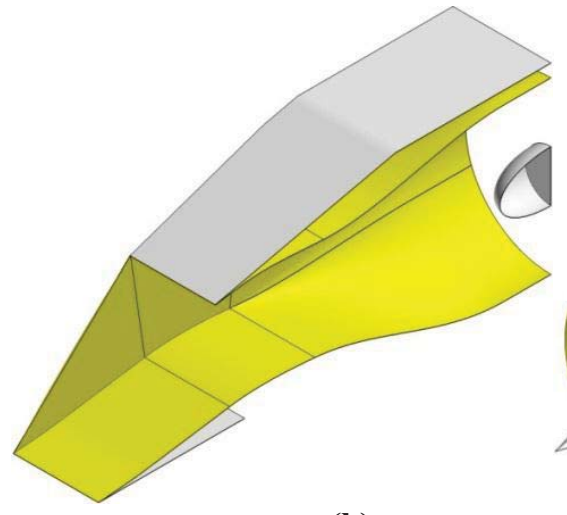

(b)

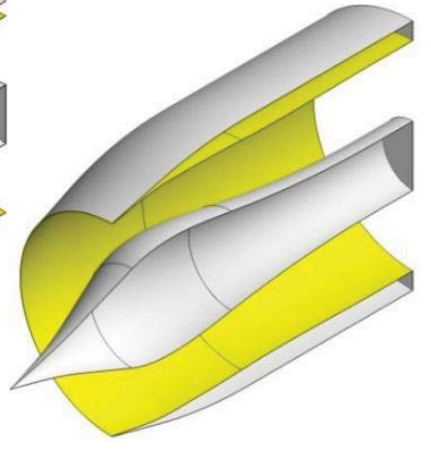

(c)

Figure 10. Images of the three traditional inlets designed by SUPIN: (a) axisymmetric pitot inlet, (b) two-dimensional inlet, and (c) axisymmetric spike inlet.

\section{A. Results from SUPIN Analyses}

The SUPIN tool was used to generate the inlet designs and compute the aerodynamic performance of the inlets. Table 1 lists some of that information for each of the inlets. The performance measures are normalized by either the freestream or engine-face conditions. The normalized capture area $\left(A_{\text {cap }} / A_{2}\right)$ and inlet length $\left(L_{\text {inlet }} / D_{2}\right)$ provide a sense of the size of the inlets. The normalized captured flow rate $\left(W_{c a p} / W_{C 2}\right)$ indicates the relative engine flow rate, and so, the relative thrust of the propulsion system. The flow rate $W_{C 2}$ is the corrected engine flow rate. The ratio $p_{t 2} / p_{t L}$ is the inlet total pressure recovery. The inlet wave drag coefficient $\left(C_{D \text { wave }}\right)$ is computed for the estimated supersonic flowfield about the cowl exterior. Thus, the value of wave drag computed by SUPIN serves mainly to compare possible wave drag levels between the different types of inlets designed for the same conditions. The normalized surface area $\left(A_{S} / A_{2}\right)$ provides a sense of the magnitude of the wetted area of the inlet. The amount of inlet surface area can also be correlated to the amount of material required for the structure of the inlet, and so, the normalized surface area can provide a sense of the relative weight of the inlets. The values of $M_{E X}, M_{l}$, and $M_{S D}$ listed in Table 1 indicate the mass-averaged Mach number just upstream of the terminal shock, the Mach number at 
the cowl lip at station 1, and the Mach number at the start of the subsonic diffuser at station SD, respectively. The values of Mach number indicate the deceleration of the flow and the level of diffusion of the flow through the inlet.

Table 1. Comparison of inlet size and performance as designed using SUPIN.

\begin{tabular}{cccccccccc}
\hline \hline Inlet Type & $\boldsymbol{A}_{\text {cap }} / \boldsymbol{A}_{\mathbf{2}}$ & $\boldsymbol{L}_{\text {inlet }} / \boldsymbol{D}_{\mathbf{2}}$ & $\boldsymbol{W}_{\text {cap }} / \boldsymbol{W}_{\boldsymbol{C} 2}$ & $\boldsymbol{p}_{\boldsymbol{t} 2} / \boldsymbol{p}_{\boldsymbol{t} \boldsymbol{L}}$ & $\boldsymbol{C}_{\boldsymbol{D} \text { wave }}$ & $\boldsymbol{A}_{\boldsymbol{S}} / \boldsymbol{A}_{\boldsymbol{2}}$ & $\boldsymbol{M}_{\boldsymbol{E X}}$ & $\boldsymbol{M}_{\boldsymbol{1}}$ & $\boldsymbol{M}_{\boldsymbol{S D}}$ \\
\hline Axisymmetric Pitot & 0.855 & 1.440 & 0.657 & 0.891 & 0.142 & 12.80 & 1.600 & 0.668 & 0.618 \\
Two-Dimensional & 0.928 & 2.655 & 0.714 & 0.968 & 0.237 & 19.96 & 1.300 & 0.786 & 0.753 \\
Axisymmetric Spike & 0.937 & 2.028 & 0.721 & 0.977 & 0.237 & 17.19 & 1.278 & 0.798 & 0.606 \\
STEX-Circular & 0.921 & 2.905 & 0.709 & 0.960 & 0.028 & 21.32 & 1.175 & 0.859 & 0.767 \\
STEX-Flattop & 0.921 & 2.749 & 0.708 & 0.960 & 0.017 & 21.45 & 1.174 & 0.859 & 0.768 \\
\hline
\end{tabular}

Some of the observations that can be made from Table 1 are as follows. Since all of the inlets were designed for the same corrected engine flow rate, the size of the capture area is directly related to the resulting total pressure recovery obtained for each inlet. A lower total pressure recovery resulted in a smaller capture area, which resulted in a smaller amount of captured airflow. Less airflow means less thrust that can be generated by the propulsion system. The axisymmetric pitot inlet has the lowest total pressure recovery since most of the total pressure losses occur across a normal shock with the Mach number ahead of the shock at $M_{E X}=1.6$. The other inlets use external supersonic compression to decelerate the Mach number prior to the terminal shock. The axisymmetric spike inlet had the highest total pressure recovery. Both STEX inlets indicate the same total pressure recovery that is lower than the two-dimensional and axisymmetric spike inlets.

The two STEX inlets show very similar performance despite the difference in the capture cross-section shape. However, the analysis methods within SUPIN do not account for cross-section shape when estimating the internal total pressure losses. SUPIN does account for the different cowl exterior shapes when estimating the cowl exterior wave drag. SUPIN indicates that the STEX-Flattop inlet has lower wave drag than the STEX-Circular inlet. The Flat-Top inlet is also slightly shorter than the STEX-Circular inlet.

The three reference inlets showed some interesting observations compared to the two STEX inlets. All three reference inlets are shorter and have less surface area than the STEX inlets. The pitot inlet was the shortest inlet with the least surface area because it had no external supersonic diffuser extending forward of the cowl lip. The reference inlets would also likely have lower weight than the STEX inlets.

The STEX inlets indicate significantly lower levels of cowl wave drag than the three reference inlets. This is in part due to the inward-turning supersonic compression of the STEX inlets. The axisymmetric inlet achieves external supersonic compression by turning the flow away from the axis-of-symmetry through conical shocks from the spike centerbody. Thus, the angle of the cowl lip has to be nearly aligned with the external supersonic diffuser flowfield to begin the turning of the flow into the inlet. This creates relatively large external cowl angles that contribute to the cowl wave drag. Further, the cowl exterior has to have this angle over the entire circumference of the cowl exterior to maintain symmetry of the flow about the axis. The STEX inlets only require the cowl lip to be aligned with the local flow in the region of the subsonic cowl lip. The external angles of the supersonic cowl lip are set lower to create a smooth variation of the cowl exterior downstream of the capture cross-section. Thus, overall, the cowl exterior angles are smaller for the STEX inlets, which lead to lower values of cowl wave drag. The pitot inlet has larger values of cowl drag than the STEX inlets because in addition to larger cowl exterior angles, the capture area is smaller, and so, there is a greater amount of forward-projecting area on the cowl exterior than for the STEX inlets. A full understanding of the cowl drag of these inlets requires integration of the inlet with the aircraft.

\section{B. Results from Wind-US CFD Analyses}

The Wind-US CFD code was used to compute steady-state flow fields for each of the inlets for several engine flow rates at and about the design engine flow rate. Table 2 lists the inlet performance measures as obtained from CFD simulations at the design engine flow rate with then engine face Mach number approximately equal to $M_{2}=$ 0.52. The inlet performance measures as calculated by SUPIN and listed in Table 1 are also listed in Table 2. The difference between the SUPIN and Wind-US values are also listed in Table 2 as percentages. The differences between SUPIN and Wind-US for the inlet flow ratio $\left(W_{2} / W_{c a p}\right)$ and the total pressure recovery $\left(p_{t 2} / p_{t L}\right)$ are likely low enough to provide verification that SUPIN can be used effectively for conceptual inlet design at least for the axisymmetric pitot and axisymmetric spike inlets. The levels of spillage above $2.0 \%$ for the STEX inlets may indicate that the inlet sizing is not correct. This results in the inlet flow ratios being below one, which pushes the terminal shock upstream and reduces the total pressure recovery. The inlet cowl wave drag coefficients indicate sizable differences that suggest the drag models within SUPIN are in need of correction. 
Table 2. Comparison of SUPIN and CFD results.

\begin{tabular}{clcccc}
\hline \hline \multicolumn{1}{c}{ Inlet } & & $\boldsymbol{W}_{2} / \boldsymbol{W}_{\text {cap }}$ & $\boldsymbol{p}_{\mathbf{t}} / \boldsymbol{p}_{\boldsymbol{t} \boldsymbol{L}}$ & $\boldsymbol{C}_{\boldsymbol{D} \text { wave }}$ & $\boldsymbol{D I S T}$ \\
\hline \multirow{3}{*}{ Axisymmetric Pitot } & SUPIN & 1.000 & 0.891 & 0.142 & - \\
& Wind-US & 0.997 & 0.895 & 0.133 & 0.016 \\
& Difference & $-0.30 \%$ & $0.45 \%$ & $-6.34 \%$ & - \\
\hline \multirow{3}{*}{ Axisymmetric Spike } & SUPIN & 1.000 & 0.977 & 0.237 & - \\
& Wind-US & 0.996 & 0.985 & 0.212 & 0.032 \\
& Difference & $-0.40 \%$ & $0.82 \%$ & $-10.55 \%$ & - \\
\hline \multirow{3}{*}{ STEX-Circular } & SUPIN & 1.000 & 0.960 & 0.028 & - \\
& Wind-US & 0.976 & 0.948 & 0.033 & 0.203 \\
& Difference & $-2.40 \%$ & $-1.25 \%$ & $17.86 \%$ & - \\
\hline \multirow{3}{*}{ STEX-Flattop } & SUPIN & 1.000 & 0.960 & 0.017 & - \\
& Wind-US & 0.976 & 0.950 & 0.042 & 0.180 \\
& Difference & $-2.40 \%$ & $-1.04 \%$ & $147.1 \%$ & - \\
\hline
\end{tabular}

Table 2 also lists a value for the total pressure distortion as represented by the distortion descriptor DIST. The distribution of the total pressure at the engine face is of interest to evaluate the compatibility of the inlet with the engine. The total pressure distribution at the engine face is interpolated from the CFD flow field onto an SAE 40probe rake in which each probe is at the centroid of an equal-area segment of the engine face. ${ }^{19}$ The inlet total pressure recovery $\left(p_{t 2} / p_{t L}\right)$ was computed as the arithmetic average of the 40 total pressure values from the probes divided by the inflow total pressure. The distortion descriptor DIST is calculated as the maximum difference of the probe values divided by the inlet total pressure recovery, or

$$
D I S T=\frac{\left[\left(p_{t} / p_{t L}\right)_{\max }-\left(p_{t} / p_{t L}\right)_{\min }\right]}{p_{t 2} / p_{t L}}
$$

Figure 11 shows the characteristic performance curves for the inlets over the range of the inlet flow ratios explored in the CFD simulations. The curves for the inlet total pressure recovery form the characteristic performance "cane" curves for each inlet. The curve for the axisymmetric pitot inlet denoted with circular symbols indicates the typical behavior of these cane curves. The design point for the inlet is at the bend of the curve and has the total pressure recovery of $p_{t 2} / p_{t L}=0.895$ associated with an inlet flow ratio of $W_{2} / W_{\text {cap }}=0.997$. The design point is at the critical operating point of the inlet for which the terminal shock is located at the cowl lip and the captured flow is at its maximum. At supercritical inlet operation, the inlet cannot take in more flow, and so, the total pressure recovery decreases to maintain flow continuity. At subcritical inlet operation, the inlet is able to spill excess flow at subsonic conditions in the region between the terminal shock and the cowl lip. The inlet flow ratio decreases with little change in the total pressure recovery. In Fig. 11, the characteristic performance curve for the axisymmetric spike inlet shows the highest total pressure recovery. The cane curves for the STEX inlets are below that of the axisymmetric spike inlet. The design point for the STEX-Circular inlet is not at the bend of that cane curve, but rather at an inlet flow ratio of $W_{2} / W_{\text {cap }}=0.976$. The cane curve for the STEX-Flattop inlet does not have the traditional shape of the cane curves of the other inlets.

Figure 11 shows plots of the inlet cowl wave drag $\left(C_{D \text { wave }}\right)$ for the CFD simulations of each inlet. The variation of the inlet cowl wave drag is linear over the range of engine flows. The STEX inlets indicate considerably lower inlet cowl wave drag than the axisymmetric pitot and axisymmetric spike inlets.

Figure 11 shows plots of the inlet total pressure distortion (DIST) for the CFD simulations of each inlet. The axisymmetric pitot and axisymmetric spike inlets indicated low levels of total pressure distortion. The STEX inlets showed considerably higher levels of total pressure distortion of which could present adverse conditions for a turbofan engine. 

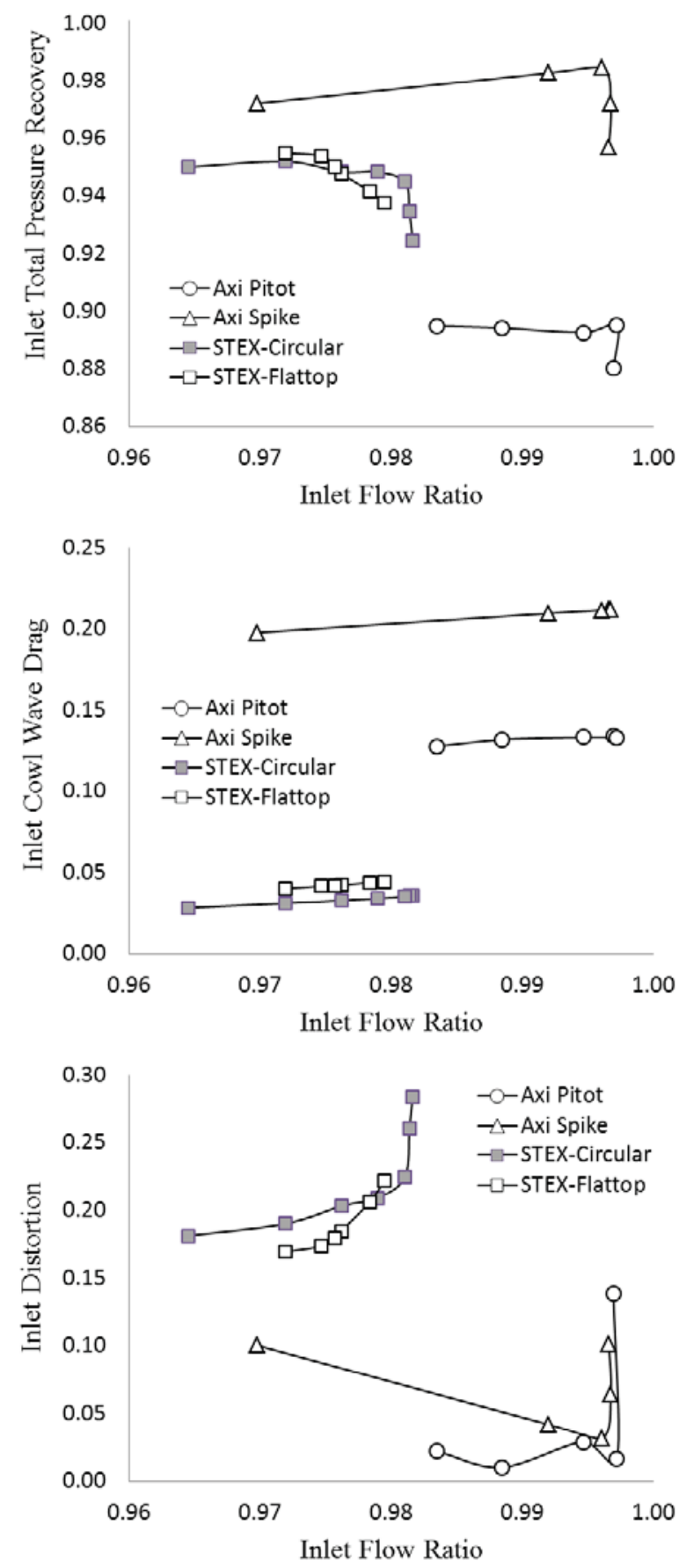

Figure 11. Characteristic performance curves from the CFD simulations of the inlets.

The CFD simulations provide the flow properties throughout the flow field, which can be used to visualize the details of the flow field. Figure 12 shows the Mach number contours on the symmetry plane of the axisymmetric pitot inlet at the critical operating condition. The normal terminal shock is located at the cowl lip station and subsonic flow is within the subsonic diffuser. The Mach number and the normalized total pressure contours at the engine face are also shown in Fig. 12. The contours indicate axisymmetric flow with some variation in the radial direction, but the flow is approximately uniform. Figure 13 shows similar images for the axisymmetric spike inlet. The boundary layers on the cowl and spike centerbody can be seen. The boundary layers appear to be the only source of non-uniformity that contributes to the total pressure distortion at the engine face for the axisymmetric pitot and axisymmetric spike inlets. 


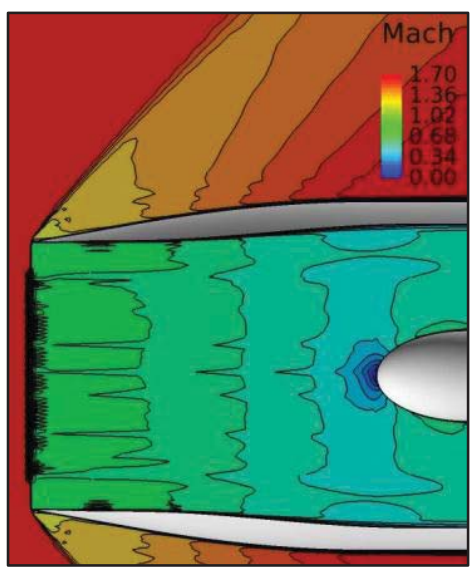

(a)

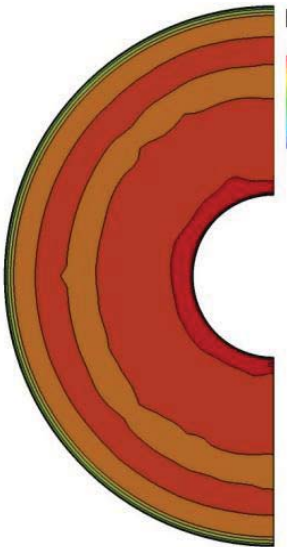

(b)

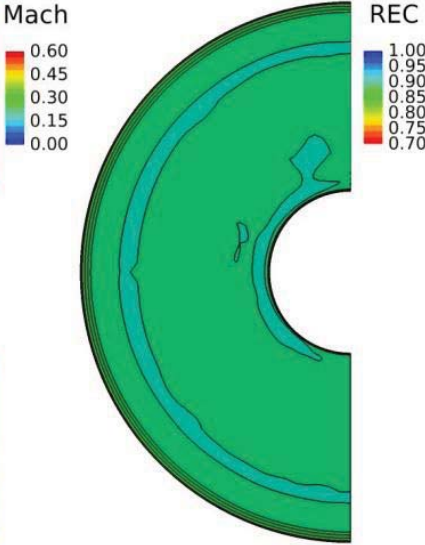

(c)

Figure 12. Images of the flowfield for the axisymmetric pitot inlet: (a) Mach number contours on the symmetry plane, (b) Mach number contours at the engine face, and (c) total pressure recovery contours at the engine face.

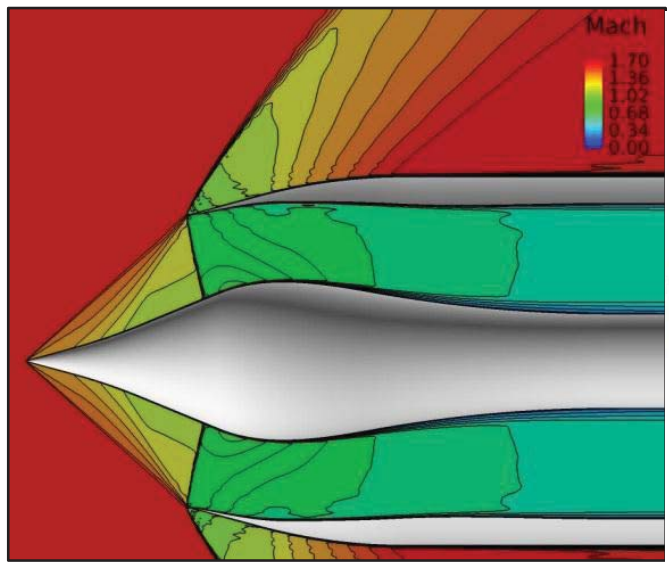

(a)

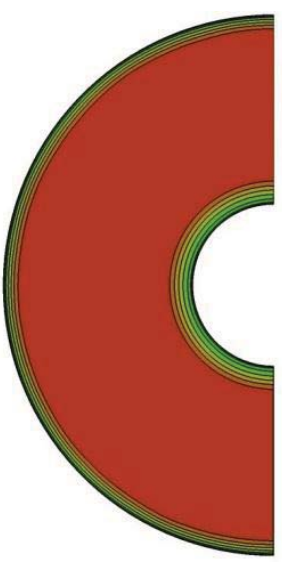

(b)

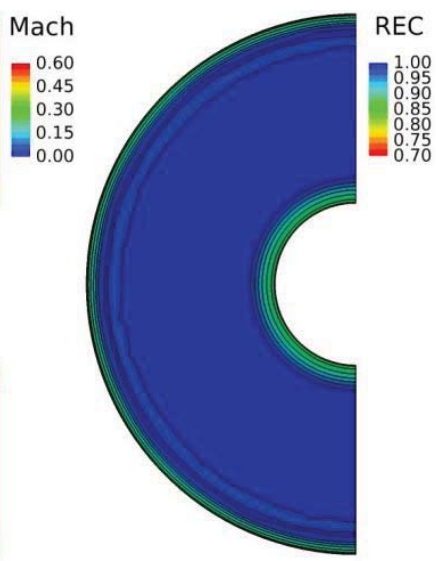

(c)

Figure 13. Images of the flowfield for the axisymmetric spike inlet: (a) Mach number contours on the symmetry plane, (b) Mach number contours at the engine face, and (c) total pressure recovery contours at the engine face.

Figure 14 shows the Mach number contours on the symmetry plane for the STEX-Circular and STEX-Flattop inlets at the critical operating point. Figure 15 shows Mach number contours on planes along the length of the inlet. A feature of the flow fields is that low-momentum regions form downstream of the throats of the inlets along the top of the inlets. This creates deficit regions at the engine faces that distort the total pressure at the engine faces. The features of the STEX-Flattop inlet are similar to those of the STEX-Circular inlet; however, the STEX-Flattop inlet positions more of the low-momentum flow toward the upper "corner" of the inlet. Figure 16 shows the Mach number and total pressure contours at the engine faces for the two STEX inlets. While the STEX-Circular inlet shows greater distortion at the top, the STEX-Flattop inlet shows that the distortion moved more to the side due to the flat and almost rectangular shape of the top portion of the inlet. 

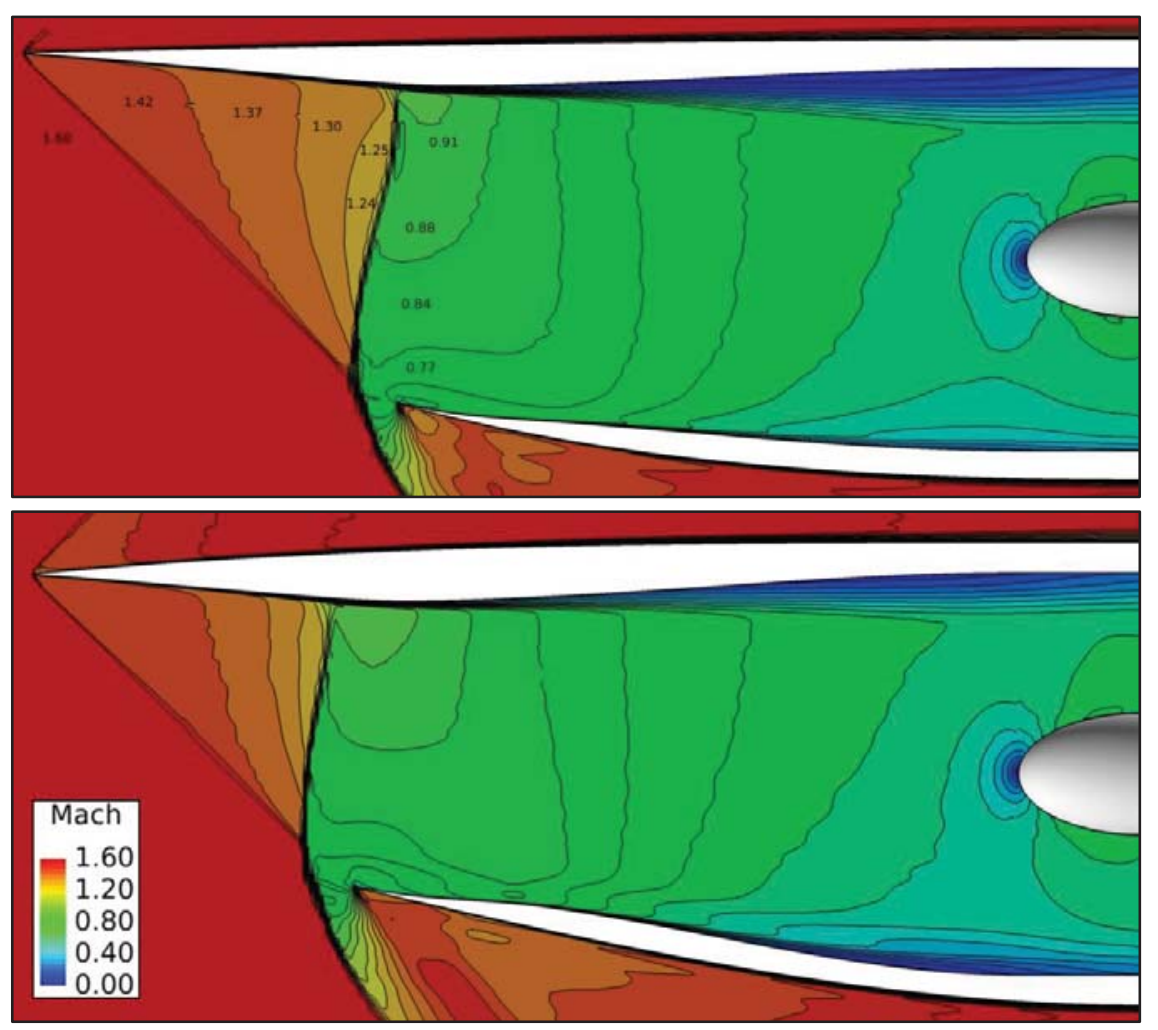

Figure 14. Mach number contours on the symmetry plane for the STEX-Circular (top) and STEX-Flattop (bottom) inlets.
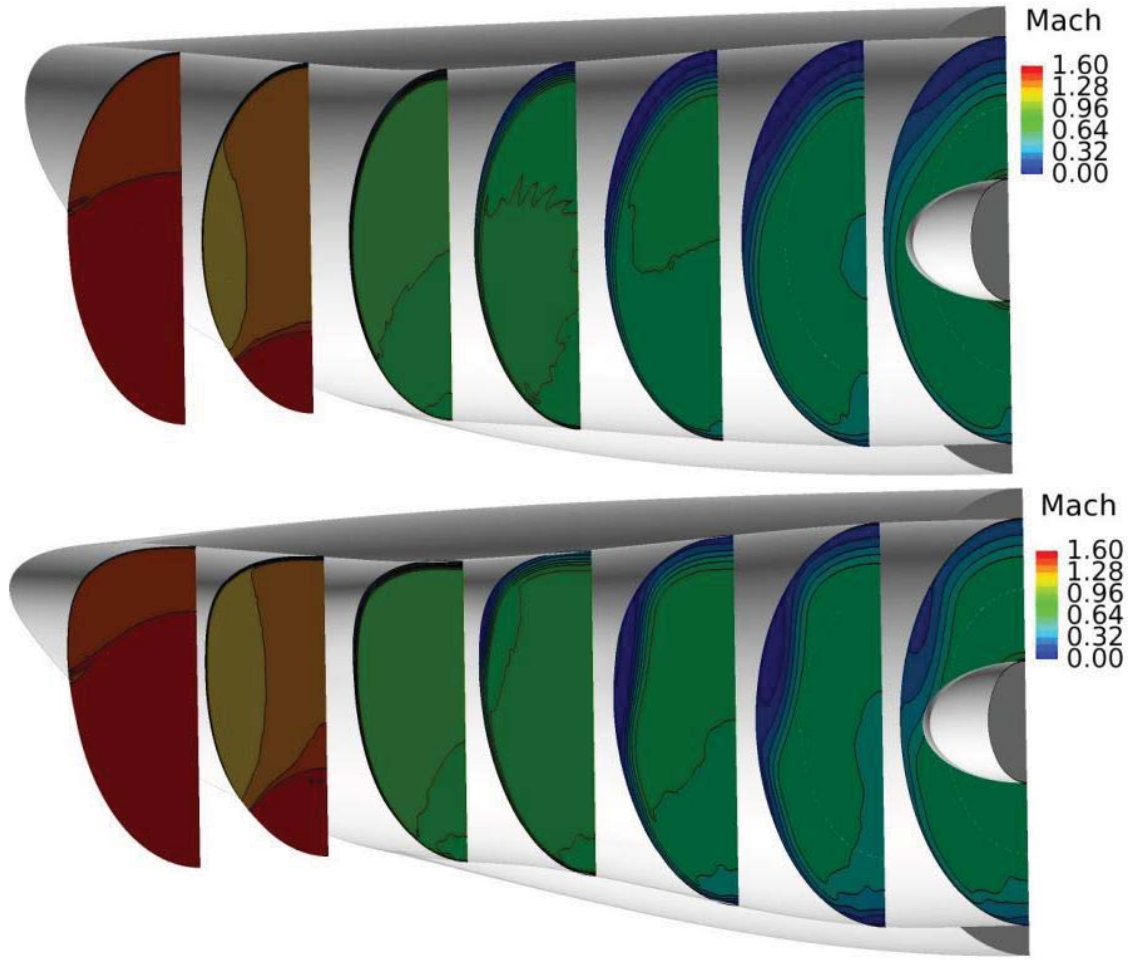

Figure 15. Mach number contours at axial stations for the STEX-Circular (top) and STEX-Flattop (bottom) inlets. 


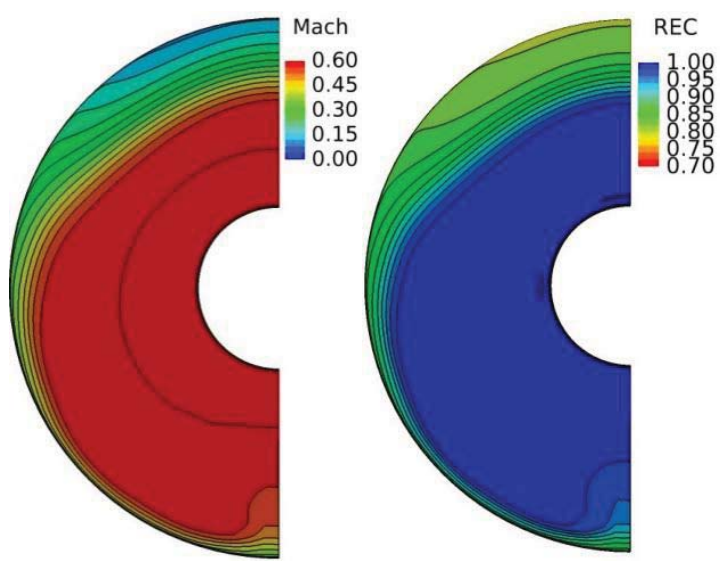

STEX-Circular

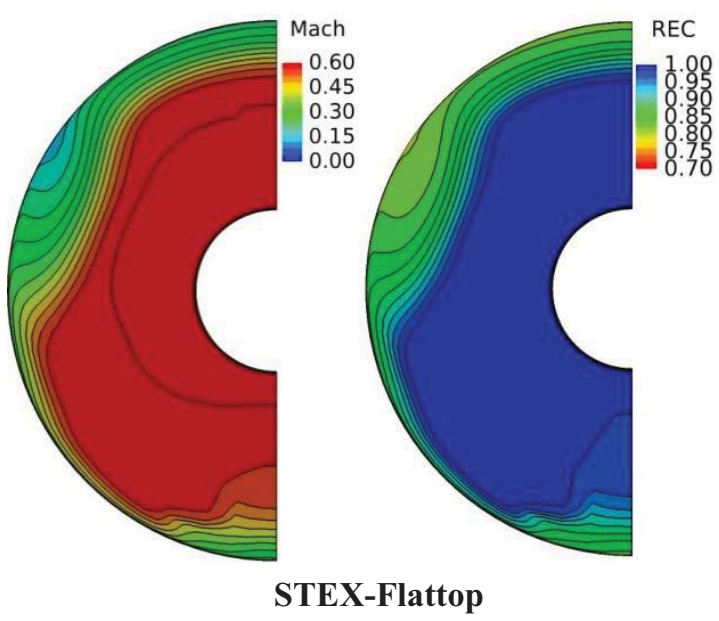

STEX-Flattop

Figure 16. Mach number and total pressure recovery contours at the engine face of the STEX-Circular (left) and STEX-Flattop (right) inlets.

\section{Exterior Sound Pressures}

A concern with supersonic commercial flight is the presence of sonic booms created by the aircraft and their impact to people and structures on the ground as the aircraft passes overhead. The ability of a commercial aircraft to fly over land supersonically with minimal sonic boom effects is considered crucial to the economic viability of such an aircraft. The sonic boom effects of the inlets studied here are approximated by examining the normalized sound pressures $\left[\left(p-p_{0}\right) / p_{0}\right]$ on a cylinder with a diameter of two engine-face diameters in which the axis of the cylinder coincides with the inlet axis. Figure 17 shows an image of the STEX-Circular inlet with the cylinder and contours of the normalized sound pressures. The black contour lines show the shock waves and Mach number contours on the symmetry plane. The terminal shock spills past the cowl lip and extends below the inlet, while above the inlet there is little presence of shock waves. The sound pressure contours on the cylinder likewise show much of the disturbances occur below the inlet. Table 3 lists the minimum, maximum, and root-mean-square of the distribution of sound pressures on the cylinder. The statistics indicate that the STEX-Circular inlet results in lower values of sound pressure than the pitot and axisymmetric inlets. This suggests that the STEX-Circular inlet would have lower sonic boom effects, although a formal analysis of the sonic boom effects is needed to provide definite conclusions. A beneficial aspect of the distribution of the sound pressure for the STEX inlet shown in Fig. 17 is that the largest disturbances are focused at the bottom of the inlet below the cowl lip. About the sides and top of the inlet, the disturbances are less. This may allow the disturbances to be directed in a certain direction by rotating the inlet about its axis. For example, if the inlet is rotated 180-degrees about the inlet axis, then the disturbances would be directed upward. On an aircraft, this would mean the disturbances would be directed up into the atmosphere rather than toward the ground. 


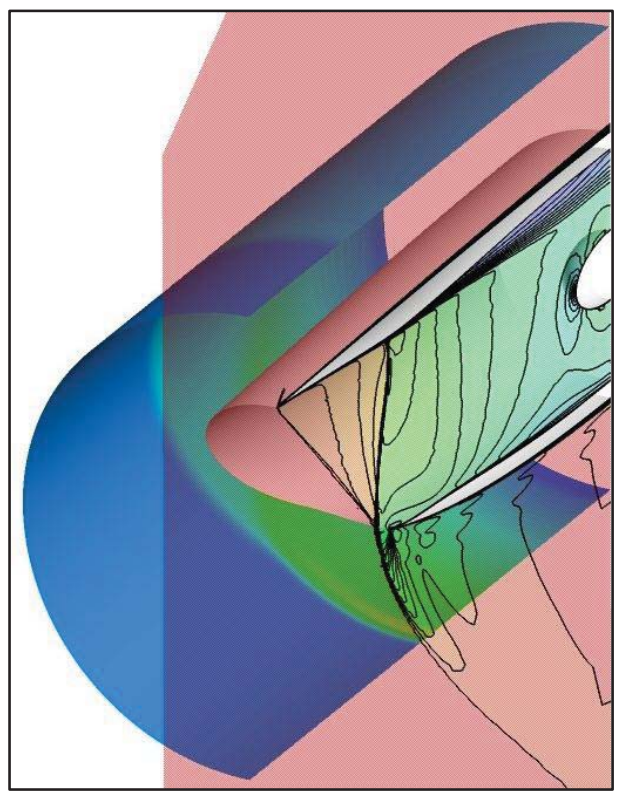

Figure 17. Sound pressure contours on a cylinder about a STEX-Circular inlet.

Table 3. Sound pressure statistics.

\begin{tabular}{lcccc}
\hline \hline & Axi Pitot & Axi Spike & STEX-Circular & STEX-Flattop \\
\hline$\Delta \boldsymbol{p}_{\min } / \boldsymbol{p}_{\boldsymbol{0}}$ & -0.009 & -0.100 & -0.022 & -0.063 \\
$\boldsymbol{\Delta} \boldsymbol{p}_{\max } / \boldsymbol{p}_{\boldsymbol{0}}$ & 0.374 & 0.606 & 0.343 & 0.380 \\
$\boldsymbol{\Delta} \boldsymbol{p}_{\text {rms }} / \boldsymbol{p}_{\boldsymbol{0}}$ & 0.171 & 0.192 & 0.072 & 0.080 \\
\hline
\end{tabular}

\section{Summary and Conclusions}

A methodology has been presented for the design of streamline-traced, external-compression (STEX) supersonic inlets for specified freestream and engine-face conditions and a specified set of input design factors. An inlet design study indicated that STEX inlets had slightly lower total pressure recovery and higher levels of total pressure distortion than axisymmetric spike inlets. Much work is needed to further understand the effects and interactions of the various design factors that are contained within the STEX inlet design methodology. This should lead to an improvement in the performance of the STEX inlets. Further improvement in the performance of the STEX inlets may be possible through the use of porous bleed and flow control devices in the throat region. The use of CFD simulations will provide a tool for understanding the flow fields of STEX inlets and the improvement of the models within SUPIN. The STEX inlets have demonstrated considerably lower levels of cowl wave drag than the traditional inlets due to the inward-turning nature of the supersonic compression. Such features also lead to lower levels of sound pressure, which may result in lower sonic boom effects. The streamline-tracing concept offers flexibility in the shape of the capture cross-section. This offers flexibility in the integration of the inlet with an aircraft, which may lead to performance and operation benefits.

\section{Acknowledgments}

The author would like to acknowledge the support of the High Speed Project of the NASA Fundamental Aeronautics Program.

\section{References}

1. Seddon, J. and E.L. Goldsmith, Intake Aerodynamics, AIAA Education Series, New York, 1985.

2. Seddon, J. and E.L. Goldsmith, editors, Practical Intake Aerodynamic Design, AIAA Education Series, New York, 1993.

3. Ferri, A. and Nucci, L.M., "Preliminary Investigation of a New Type of Supersonic Inlet," NACA RM L6J31, November 1946. 
4. Hawkens, J.E., "YF-16 Inlet Design and Performance," AIAA-1974-1062, October 1974.

5. Imfeld, W.F., "Development Program for the F-15 Inlet," AIAA Journal of Aircraft, Vol. 13, No. 4, p. 286-291, April 1976.

6. Porcher, C.E. and Thebiay, F.J., "Development of the Variable Geometry Inlet for the B-58 Airplane," SAE 595N, October 1962.

7. Evvard, J.C. and Maslen, S.H., "Three-Dimensional Supersonic Nozzles and Inlets of Arbitrary Exit Cross-Section," NACA TN 2688, April 1952.

8. Mölder, S. and Szpiro, E.J., "Busemann Inlet for Hypersonic Speeds", AIAA Journal of Spacecraft and Rockets, Vol. 3, No. 8, pp. 1303-1304, August 1966.

9. Van Wie, D. and S. Mölder, “Applications of Busemann Inlet Designs for Flight at Hypersonic Speeds," AIAA-1992-1210, February 1992.

10. Billig, F.S., Baurle, R.A., Tam, C.-J., and Wornom, S.F., "Design and Analysis of Streamline Traced Hypersonic Inlets," AIAA-1999-4974, November 1999.

11. Sanders, B.W., Koncsek, J.L, and Hedges, L.S., "Supersonic External-Compression Diffuser and Method for Designing Same," Patent 6793175, September 2004.

12. Slater, J.W., Davis, D.O., Sanders, B.W., and Weir, L.J., "Role of CFD in the Aerodynamic Design and Analysis of the Parametric Inlet," ISABE-2005-1168, 2005.

13. Garzon, G.A., "Use of a Translating Cowl on a SSBJ for Improved Takeoff Performance," AIAA-2007-0025, January 2007.

14. Rodriguez, D.L., "Propulsion / Airframe Integration and Optimization on a Supersonic Business Jet," AIAA 2007-1048, January 2007.

15. Anderson, J.D., Jr., Modern Compressible Flow, McGraw-Hill Book Company, New York, 1982.

16. Koncsek, J. L., "An Approach to Conformal Inlet Diffuser Design for Integrated Propulsion Systems," AIAA-1981-1395, July 1981 .

17. Walatka, P.P., Buning, P.G., Pierce, L., and Elson, P.A., “PLOT3D User’s Manual,” NASA-TM-101067, March 1990.

18. Mani, M., Cary, A., and Ramakrishnan, S., "A Structured and Hybrid-Unstructured Grid Euler and Navier-Stokes Solver for General Geometry," AIAA-2004-0524, January 2004.

19. SAE, Aerospace Standard (AS) 755, "Aircraft Propulsion System Performance Station Designation and Nomenclature," December 1997. 